\title{
Synthesis of tert-butyl 4-((2-methoxy-4-(methoxycarbonyl) phenoxy) methyl) piperidine-1-carboxylate
}

\author{
Min Wang ${ }^{1}$, Wenhui Wang ${ }^{1}$, Qidong Tang ${ }^{\mathrm{a}, *}$, Shan $\mathrm{Xu}^{\mathrm{b}}$ \\ School of Pharmacy, Jiangxi Science \& Technology Normal University, Nanchang 330013, China \\ a564032414@qq.com, bshanxu9891@126.com
}

Keywords: tert-butyl 4-((2-methoxy-4-(methoxycarbonyl) phenoxy) methyl) piperidine-1carboxylate; Vandetanib; Synthesis.

\begin{abstract}
Tert-butyl 4-((2-methoxy-4-(methoxycarbonyl) phenoxy) methyl) piperidine-1-carboxylate (1) is the key intermediate of Vandetanib. It was synthesized from piperidin-4-ylmethanol (2) through three steps Including acylation, sulfonation and substitution. The structures and the synthetic route were determined by MS and 1HNMR.And the synthetic method was optimized. The total yield of the three steps was $20.2 \%$.
\end{abstract}

\section{Introduction}

Cancer is a widespread, complex, and lethal disease. It is a group of different diseases characterized by uncon-trolled cellular growth, tissue damage, invasion and metastases ${ }^{[1]}$. In 2008 , 7.6 million people died of cancer (around 13\% of all deaths), and this number is projected to increase with an estimated 13.1 million in 2030. According to an estimate from the American Cancer Society, a total of 1638910 new cancer cases and 577190 deaths from cancer could occur in the United States this year ${ }^{[2]}$. Despite the efforts to discover and develop small molecule anticancer drugs in the last decade $^{[3-6]}$, development of new antitumor agents with improved tumor selectivity, efficiency, and safety remains desirable. Recently, a number of new quinoline derivatives with excellent antitumor activity have been reported ${ }^{[7-16]}$. Vandetanib (a) is one of the quinoline derivatives and a kind of tryrosine kinase inhibitors. It is a potent inhibitor of VEGF RTK and also has some activity against epidermal growth factor (EGF) RTK ${ }^{[17]}$. It inhibits the effects of VEGF and is of interest for its antiangiogenic and/or vascular permeability effect ${ }^{[18]}$. It was approved for the treatment of metastatic medullary thyroid cancer (MTC) by U. S. Food and Drug Administration (FDA) on June 4, 2011.

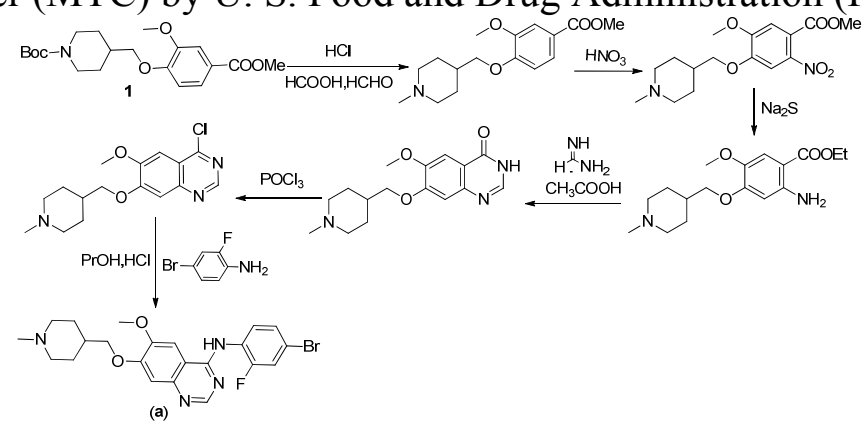

Fig. 1 Structures of compounds and synthetic route of Vandetanib

Vandetanib was synthesized from Tert-butyl 4-((2-methoxy-4-(methoxycarbonyl) phenoxy) methyl) piperidine-1-carboxylate (1) through six steps including deprotection, nitration, reduction, cyclization, chlorination and substitution. So it aslo provide a vital role in the subsequent rection. Sructures of compounds and synthetic route of Vandetanib were shown in Fig.1.

\section{Materials and methods}

NMR spectra were performed using Bruker $400 \mathrm{MHz}$ spectrometers (Bruker Bioscience, Billerica, MA, USA) with TMS as an internal standard. Mass spectra (MS) were taken in ESI mode on Agilent 1100 LC-MS (Agilent, Palo Alto, CA, USA). All the materials were obtained from commercial 
suppliers and used without purification, unless otherwise specified. Yields were not optimized. TLC analysis was carried out on silica gel plates GF254 (Qindao Haiyang Chemical, China)

\section{Synthesis of compounds}

The structures and the synthetic route were shown in Scheme 1.<smiles>OCC1CCNCC1</smiles>

2<smiles>CC(C)(C)OC(=O)[C@@H]1CC(CO)CCN1C(=O)OC(C)(C)C</smiles>

3

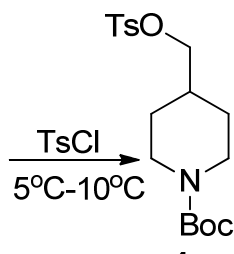

4

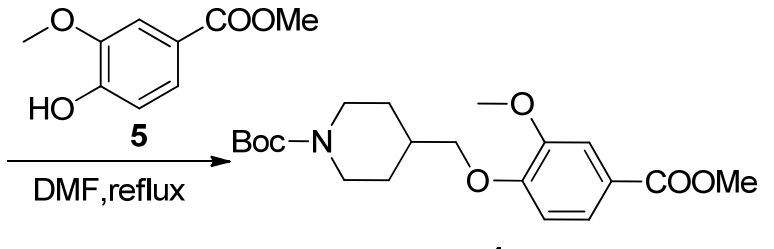

1

Scheme 1 . The synthetic route of Compound 1

\subsection{Tert-butyl 4-(hydroxymethyl)piperidine-1-carboxylate(3)}

4-Hydroxymethylpiperidine $(2)(2.7 \mathrm{~g}, 23.5 \mathrm{mmol})$ and di-tert-butyldicarbonate $(5.12 \mathrm{~g}, 23.5 \mathrm{mmol})$ were dissolved in THF $(30 \mathrm{~mL})$ and the solution was stired 8 hours at room temperature. The mixture was concentrated in vacuo and the residue was dissolved in ether.The either solution was washed with water and then with brine,and dried over sodium sulfate.Evaporation of the solvents and gave a residue of $4.0 \mathrm{~g}$ tert-butyl 4-(hydroxymethyl)piperidine-1-carboxylate. yield:85.0\%. ESI-MS $\mathrm{m} / \mathrm{z}: 216.3(\mathrm{M}+\mathrm{H})^{+}$.

\subsection{Tert-butyl 4-((tosyloxy)methyl)piperidine-1-carboxylate(4)}

The compound $3(2.55 \mathrm{~g}, 12.6 \mathrm{mmol})$ was dissolved in pyridine $(20 \mathrm{~mL})$ and the solution was cooled to $0^{\circ}$ C.P-Toluenesulfonyl chloride $(2.38 \mathrm{~g}, 12.6 \mathrm{mmol})$ was then added to the solution and the mixture was stired at $5{ }^{\circ} \mathrm{C}$ for 10 hours. The mixture was pured into water and extracted into ethyl acetate. The ethylacetate extract was washed with 5 percent $\mathrm{HCl}$,with water,and with brine.The ethyl acetate was then dried over sodium sulfate and then evaporated.Crystallization from actate-hexane gave tert-butyl 4-((tosyloxy)methyl)piperidine-1-carboxylate $2.09 \mathrm{~g}$. yield:45.1\%.m.p.71 ${ }^{\circ} \mathrm{C} \quad-72 \quad{ }^{\circ} \mathrm{C}$. ESI-MS $\mathrm{m} / \mathrm{z}: 370.5(\mathrm{M}+\mathrm{H})^{+}$.

\subsection{Tert-butyl}

\section{4-((2-methoxy-4-(methoxycarbonyl)phenoxy)methyl)piperidine-1-carboxylate(1)}

Methyl 4-hydroxy-3-methoxybenzoate $(5)(0.91 \mathrm{~g}, 5 \mathrm{mmol})$ and tert-butyl 4-((tosyloxy) methyl) piperidine-1-carboxylate (4) $(2.0 \mathrm{~g}, 5.5 \mathrm{mmol})$ were dissolved in $\mathrm{DMF}(5 \mathrm{~mL})$. Then potassium carbonate $(0.14 \mathrm{~g}, 10 \mathrm{mmol})$ was added into the reaction system, then heated to $153{ }^{\circ} \mathrm{C}$ and stirred for 10 hours. After cooling to room temperature, the mixture was pured into water and extracted into ethyl acetate. The ethyl acetate was then dried over sodium sulfate and then evaporated. We can get $0.97 \mathrm{~g}$ tert-butyl 4-((2-methoxy-4- (methoxycarbonyl) phenoxy) methyl) piperidine-1-carboxylate (1). yield:

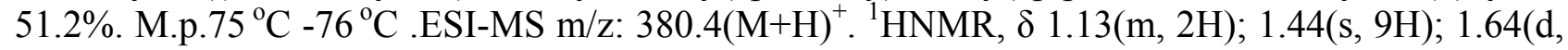
$2 \mathrm{H}) ; 1.75(\mathrm{~m}, 2 \mathrm{H}) ; 2.44(\mathrm{~s}, 3 \mathrm{H}) ; 2.55(\mathrm{~m}, 2 \mathrm{H}) ; 3.84(\mathrm{~d}, 2 \mathrm{H}) ; 4.12(\mathrm{~s}, 2 \mathrm{H}) ; 7.34(\mathrm{~d}, 2 \mathrm{H}) ; 7.80(\mathrm{~d}, 2 \mathrm{H})$.

\section{Conclusions}

In conclusion, the compound 1 is a key intermediate of Vandetanib. It was synthesized from 4-Hydroxymethylpiperidine (2) through three steps including acylation, sulfonation and substitution. The synthetic method of compound 1 and the reactions conditions were optimized, after recrystallization, the purity of the product was higher. Its structure was confirmed by MS spectrum and ${ }^{1} \mathrm{HNMR}$.

\section{Acknowledgments}

We gratefully acknowledge the generous support provided by The National Natural Science Funds (No.80140357) Project supported by the Natural Science Foundation of Jiangxi Province (No. 20142BAB215020) and Program of Key Laboratory of Drug Design and Optimization, Jiangxi Science \& Technology Normal University (300098010306). 


\section{Reference}

[1] Wei L, Malhotra S V. Synthesis and cytotoxicity evaluation of novel pyrido [3, 4-d] pyrimidine derivatives as potential anticancer agents[J]. Medicinal Chemistry Communications, 2012, 3(10): 1250-1257.

[2] Samadi A K, Bazzill J, Zhang X, et al. Novel withanolides target medullary thyroid cancer through inhibition of both RET phosphorylation and the mammalian target of rapamycin pathway[J]. Surgery, 2012, 152(6): 1238-1247.

[3] You W K, Sennino B, Williamson C W, et al. VEGF and c-Met blockade amplify angiogenesis inhibition in pancreatic islet cancer[J]. Cancer research, 2011, 71(14): 4758-4768.

[4] Dayyani F, Gallick G E, Logothetis C J, et al. Novel therapies for metastatic castrate-resistant prostate cancer[J]. Journal of the National Cancer Institute, 2011, 103(22): 1665-1675.

[5] Zillhardt M, Park S M, Romero I L, et al. Foretinib (GSK1363089), an orally available multikinase inhibitor of c-Met and VEGFR-2, blocks proliferation, induces anoikis, and impairs ovarian cancer metastasis[J]. Clinical Cancer Research, 2011, 17(12): 4042-4051.

[6] Hoelder S, Clarke P A, Workman P. Discovery of small molecule cancer drugs: successes, challenges and opportunities[J]. Molecular oncology, 2012, 6(2): 155-176.

[7] Yakes F M , Chen J, Tan J,et al. Cabozantinib (XL184), a novel MET and VEGFR2 inhibitor, simultaneously suppresses metastasis, angiogenesis, and tumor growth[J].Molecular Cancer Therapeutics ,2011,10 (12): 2298-2308.

[8] Mannion M, Raeppel S, Claridge S, et al. N-(4-(6, 7-Disubstituted -quinolin-4- yloxy)-3fluorophenyl)-2-oxo-3-phenylimidazolidine-1-carboxamides: a novel series of dual c-Met/VEGFR2 receptor tyrosine kinase inhibitors[J]. Bioorganic \& Medcinal Chemistry Letters, 2009 , 19(23): 6552-6556.

[9] D’Angelo N D, Bellon S F, Booker S K, Y.et al. Structure of c-met with pyrimidone inhibitor [J]. Journal of Medicinal Chemistry, 2008 (51) :5766-5779.

[10] Kung P P, Funk L, Meng J, et al. Structure activity relationships of quinoline-containing c-Met inhibitors[J]. Journal of Medicinal Chemistry, 2008 (43) :1321-1329.

[11] Kataoka Y, Mukohara T, Tomioka H, et al. Foretinib (GSK1363089), a multi-kinase inhibitor of MET and VEGFRs, inhibits growth of gastric cancer cell lines by blocking inter-receptor tyrosine kinase networks[J]. Investigational new drugs, 2012, 30(4): 1352-1360.

[12] Norman M H, Liu L B, Lee M, et al. Crystal structure of the vegfr2 kinase domain in complex wit pyrazolone inhibitor [J]. Journal of Medicinal Chemistry, 2012 (55) :1858-1867.

[13] Cecchi F, Rabe D C, Bottaro D P. Targeting the HGF/Met signalling pathway in cancer[J]. European journal of cancer, 2010, 46(7): 1260-1270.

[14] I. González-Sánchez, Solano J D , Loza-Mejía M A , et al. Antineoplastic activity of the thiazolo[5,4-b]quinoline derivative D3CLP in K-562 cells is mediated through effector caspases activation[J]. Journal of Medicinal Chemistry, 2011(46):2102-2108.

[15] Abonia R, Insuasty D, Castillo J, et al. Synthesis of novel quinoline-2-one based chalcones of potential anti-tumor activity[J]. European journal of medicinal chemistry, 2012, 57: 29-40.

[16] Qian F, Engst S, Yamaguchi K, et al. Inhibition of tumor cell growth, invasion, and metastasis by EXEL-2880 (XL880, GSK1363089), a novel inhibitor of HGF and VEGF receptor tyrosine kinases[J]. Cancer research, 2009, 69(20): 8009-8016.

[17] Rodon J, Dienstmann R, Serra V, et al. Development of PI3K inhibitors: lessons learned from early clinical trials[J]. Nature Reviews Clinical Oncology, 2013, 10(3): 143-153.

[18] Vanhaesebroeck B, Stephens L, Hawkins P. PI3K signalling: the path to discovery and understanding[J]. Nature Reviews Molecular Cell Biology, 2012, 13(3):195-203. 